\title{
O PÚBLICO E O PRIVADO: TRANSFORMAÇÕES DA MAGNA DIVISIO JURÍDICA NA SOCIEDADE DA INFORMAÇÃO
}

\author{
Ronny Max Machado* \\ Osmar Fernando Gonçalves Barreto** \\ Paulo Ferreira da Cunha*s*
}

SUMÁRIO: Introdução; 2 Direito público e direito privado: O surgimento da Magna Divisio jurídica no Ocidente; 2.1 Da dicotomia à Magna Divisio; 2.2 Os conceitos de público e privado; 3 Os impactos da sociedade da informação no direito; 4 As transformações na Magna Divisio público/privado na sociedade da Informação; 5 Conclusão; Referências.

RESUMO: As ramificações do Direito estão diretamente ligadas à sua atuação na vida de cada ser humano. O processo de divisão destes ramos ao longo do tempo foi paulatino: num primeiro momento, era uma divisão entre o espaço público de proteção e outro que visava a regulação da vida privada. As épocas históricas fizeram com que as primeiras classificações fossem objeto de uma reflexão e ganhassem novas interpretações segundo as necessidades de cada um desses períodos. O panorama atual é o da sociedade da informação, que introduz a relevância da informação para o progresso social. Assim, por meio de uma metodologia de revisão bibliográfica, o presente artigo tem por objetivo refletir acerca de algumas questões que envolvem os impactos da sociedade da informação no direito, em especial, as mudanças sofridas na concepção de público e privado. Procurando alertar para alguns problemas que parecem sofismados pelo otimismo imperante resultante das novidades, e discernir alguns tipos alternativos e conflitantes de privatismo e publicismo num tempo de confusão de paradigmas. Chegou-se a conclusão de que a sociedade da informação interferiu na concepção clássica da divisão entre espaço público e o privado e serviu para diluir e, quiçá, vir um dia a acabar com a delimitação entre aludidos espaços.

PALAVRAS-CHAVE: Direito público; Direito privado; Sociedade da informação.

\footnotetext{
"Mestre em Direito da Sociedade da Informação do Centro Universitário das Faculdades Metropolitanas Unidas, São Paulo, Brasil. E-mail: ronnymaxm@yahoo.com.br

**Advogado. Docente de Direito do Trabalho da Universidade Guarulhos (UNG/SP). Bolsista da Funadesp na Fadisp. Bolsista/Pesquisador CAPES, Brasil.

${ }_{* * *}^{* *}$ Docente Catedrático e Diretor do Instituto Jurídico Interdisciplinar da Faculdade de Direito da Universidade do Porto, Antigo Professor de Direito Internacional na graduação e de Teoria do Direito na Sociedade da informaçãono Programa de Mestrado em Direito da Sociedade da Informação da FMU. Brasil.
} 


\title{
THE PUBLIC AND THE PRIVATE: TRANSFORMATION IN THE JUDICIAL MAGNA DIVISIO IN INFORMATION SOCIETY
}

\begin{abstract}
The branches of the Law are directly linked to the life of each human being. The process of such divisions was slow throughout time. At first, there was the divide between the public space of protection and another aiming at the regulation of private life. The first classifications have been discussed and new interpretations were given according to the needs of each historical period. Contemporary view is underlined by the information society that introduces the relevance of information for social progress. Through a bibliographical review, current paper reflects on certain issues that involve the impacts of the society of information on Law, especially within the concept of the public and the private. Several issues will be raised which seem to be exaggeratingly exulted by optimism through novelty. Several types of alternatives and conflicting issues on the private and public stance will be debated in a period of paradigm confusion. Results show that information society intervened in the classical concept of the division between public and private space and diluted the divide, which, in the future, will come to an end.
\end{abstract}

KEY WORDS: Public law; Private law; information society.

\section{EL PÚBLICO Y ELL PRIVADO: TRANSFORMACIONES DE LA MAGNA DIVISIO JURÍDICA EN LA SOCIEDAD DE LA INFORMACIÓN}

RESUMEN: Las ramificaciones del Derecho están directamente ligadas a su actuación en la vida de cada ser humano. El proceso de división de estas ramas a lo largo del tempo fue gradual: en un primer momento, era una división entre el espacio público de protección y otro que visaba la reglamentación de la vida privada. Las épocas históricas hicieron con que las primeras clasificaciones fuesen objeto de una reflexión y ganasen nuevas interpretaciones según las necesidades de cada uno de esos períodos. El panorama actual es el de la sociedad de la información, que introduce la relevancia de la información para el progreso social. Así, por intermedio de una metodología de revisión bibliográfica, en el presente artículo se tiene por objetivo reflexionar acerca de algunas cuestiones que involucran los impactos de la sociedad de la información en el derecho, en especial, los cambios experimentados en la concepción de público y privado. Buscando advertir para algunos problemas que parecen poseer sofistería por el optimismo imperante resultante de las novedades, y discernir algunos tipos alternativos y conflictivos de privado y público en un tiempo de confusión de paradigmas. Se ha llegado a la conclusión de que la sociedad de la información interfirió en la concepción clásica de la división entre espacio público y el privado y sirvió para diluir y, quizá, venir un día a acabar con la delimitación entre aludidos espacios.

PALABRAS CLAVE: Derecho público; Derecho privado; Sociedad de la información. 


\section{INTRODUÇÃO}

O tema do presente artigo é a transformação da dicotomia entre o público e o privado, e em especial se refletirá sobre como tal mudança sofreu impactos do advento da sociedade da informação.

Trataremos o tema a partir de uma perspectiva essencialmente jurídica, pois outras há, e mesmo a jurídica não prescinde de algumas delas, desde logo sociológicas, como tela de fundo, como aponta Anthony Giddens..$^{04}$

Desta forma, analisam-se livros, artigos acadêmicos, legislação e notícias da internet relacionadas à temática, com a finalidade de verificar qual a interpretação de alguns estudiosos de referência acerca do assunto, para, a partir daí desenvolver algumas ideias próprias.

Um aspecto a ser considerado na pesquisa aborda o crescimento paulatino das sociedades, a informação foi pulverizada e seu alcance estabeleceu aumento no tocante à acessibilidade, fazendo com que de certa maneira crescesse e incluísse, muito embora, deve se ressaltar que ainda existem milhões de excluídos.

Destaca-se, também, a possibilidade de ser informado e de conhecer, que por sua vez estabeleceu um pensamento voltado aos grupos minoritários e seus respectivos sistemas jurídicos protetivos de organização, cogitando-se assim o seu reconhecimento em quanto grupo e sistema regulatório.

Diante das posições doutrinárias a serem estudadas, e tendo em vista que o enfoque da pesquisa é a análise da transformação do público e privado nas suas origens até a atualidade, denominada sociedade da informação, chega-se, prima facie, à formulação de alguns problemas muito evidentes e elementares, tais como:

a) quais as interferências da sociedade da informação no espaço público e privado?

b) Quais os efeitos de tais interferências e como isso se reflete no direito?

Deste modo, a estrutura do trabalho dar-se-á da seguinte maneira: (II) $\mathrm{O}$ direito público e direito privado: O surgimento da Magna Divisio no Ocidente, passando pelos conceitos de "público" e "privado", assim como de "dicotomia" (III) Os impactos da Sociedade da Informação no Direito, com a intenção de analisar o impacto das tecnologias e da comunicação no Direito, (IV) As transformações na Magna Divisio público/privado na Sociedade da Informação a fim de melhor se entender os efeitos de tais mudanças, seguido da conclusão e das referências

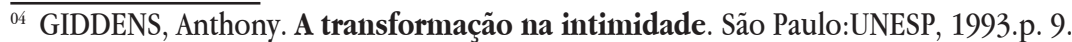


teóricas de pesquisa, que embasaram o presente estudo.

Por fim, a oscilação nas fronteiras entre público e privado necessitarão cada vez mais de processos de reflexão e harmonização. Assim temos, como objetivos, a análise de algumas questões que envolvem os efeitos da sociedade da informação no Direito, bem como as alterações provocadas na concepção de público e privado.

\section{DIREITO PÚBLICO E DIREITO PRIVADO: O SURGIMENTO DA MAGNA DIVISIO JURÍDICA NO OCIDENTE}

Na sociedade existem os espaços privados, notadamente representados pela família e sociedade civil (embora se possa perguntar se todo o social já não tem elementos de publicidade e publicização), ao passo que também existem os espaços públicos nos quais, por meio do agir comunicativo, se propiciaria a intermediação entre sociedade e Estado. Entremeando esta inter-relação atuariam os direitos fundamentais que "irradiam seus efeitos por meio de mediação legislativa" 05 , para de um lado assegurar o princípio da autonomia privada e propriedade, e de outro o exercício das liberdades públicas.

A restituição do público e do privado, como esferas de informação e de conteúdo simbólico amplamente desvinculadas de referenciais físicos e cada vez mais interligadas às crescentes tecnologias da comunicação e dos fluxos de informação, estão criando uma situação muito fluida em que os limites entre estes espaços são imprecisos e em frequente mutação. As fronteiras que se encontram em qualquer momento são porosas, contestáveis e sujeitas a negociação (ainda que por vezes simplesmente intelectual) e disputas constantes.

\subsection{DA DICOTOMIA À MAGNA DIVISIO}

Intentemos, antes de mais um procedimento de nova tópica, à maneira de um Francisco Puy. ${ }^{06}$ Vamos ver os usos admitidos. Se singelamente formos procurar a um dicionário corrente, mas conceituado, o conceito de dicotomia, obteremos que ela será algo como a divisão de um elemento em duas partes, em geral contrárias, contraditórias, opostas, como a noite e o dia, o bem e o mal, o preto e o branco, o

${ }^{05}$ SILVA, Virgílio Afonso da. A constitucionalização do direito: Os direitos fundamentais nas relações entre particulares. São Paulo: Malheiros, 2005. p. 89

${ }^{06}$ PUY, Francisco. Tópica Jurídica. Tópica de Expressiones. México: Porrúa, 2006. 
céu e o inferno etc. Com origem no grego dikbotomía, indica uma classificação que é fundamentada em uma divisão entre dois elementos. ${ }^{07}$

No âmbito da teologia, os dicotomistas acreditam que o ser humano é dividido em duas partes: corpo e alma (sendo que para eles, alma e espírito são sinônimos). Por outro lado, os tricotomistas contemplam o ser humano em três vertentes: corpo, alma e espírito.

No ramo da linguística, o suíço Ferdinand, ${ }^{08}$ abordou quatro dicotomias, sendo elas: sincronia e diacronia, língua e fala, significado e significante, sintagma e paradigma.

$\mathrm{Na}$ biologia também se estuda a dicotomia, principalmente no que tange a divisão de uma célula em duas, dando cada uma, origem a outras células. Ainda na botânica, a tricotomia indica um órgão de uma planta que é subdividido em três.

Por fim, existe o entendimento de que há em alguns casos uma falsa dicotomia, pois, via de regra, a dicotomia mostra uma situação com dois pontos de vista alternativos, e são colocados como se fossem as únicas opções, quando na realidade podem existir outras opções que não foram levadas em consideração, ou podem as duas ser escolhidas juntas.

$\mathrm{Na}$ política, ou melhor, na politologia ou ciência política avulta uma dicotomia que também é conhecida (como várias outras, aliás) por oposição binária: entre direita e esquerda. E a propósito dela tem corrido rios de tinta. ${ }^{99}$ Para Bobbio: "[...] de um lado estão aqueles que consideram que os homens são mais iguais que desiguais, de outro os que consideram que são mais desiguais que iguais" ${ }^{10}$ Mas há 1001 matizes entre uma coisa e outra.

Se a dicotomia aparenta pelo menos ser estática e sem solução dialética (é dual, é biunívoca etc.) é "a divisão suprema tradicional do universo jurídico, aquela que distingue Direito Publico e Direito Privado. Trata-se de uma distinção para o qual não foi achado até hoje um critério absolutamente satisfatório e de uma distinção que continua a ser polémica". ${ }^{11}$ Já a ideia de Magna Divisio não necessariamente opõe inelutavelmente os dois termos do conjunto. Magna divisio é o critério usado

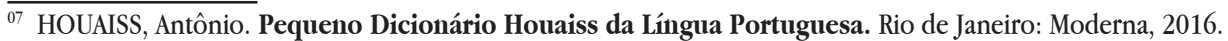

${ }^{08}$ SAUSSURE, Ferdinand. Curso de linguística geral. 26. ed. Tradução de Antônio Chelini, José Paulo Paes e Izidoro Blikstein. São Paulo: Cultrix, 1995.

${ }^{09}$ CUNHA, Paulo Ferreira da. Repensar a Política. Ciência \& Ideologia, 2. ed. Coimbra: Almedina, 2007.

${ }^{10}$ BOBBIO, Norberto. Direita e Esquerda. São Paulo: UNESP, 2001.

${ }^{11}$ MACHADO, João Baptista. Introdução ao Direito e ao Discurso Legitimador. Almedina, 2016. p. 65.
} 
por autores como João Baptista Machado, ${ }^{12}$ no seu muito original Introdução ao Direito e ao Discurso legitimador, conforme se depreende a seguir:

Nos termos deste critério, o direito público caracteriza-se pelo factos de, nas relações por ele reguladas, se verifica o exercício de um poder de autoridade pública (publica potestas). Assim seria do direito publico aquelas normas que regulam a organização e a atividade do Estado e dos outros entes públicos menores (autarquias regionais e locais), as relações desses entes públicos entre si no exercício dos poderes que lhes competem, bem como as relações dos entes públicos enquanto revestidos de poder de autoridade (revestidos de publica potestas) como os particulares [...]. Diferentemente, as normas de direito privado seriam aquelas que regulam as relações em que as partes aparecem numa posição de igualdade oi paridade. Regulam, portanto, as relações entre os particulares, ou entre, os particulares e os entes públicos, quando estes não intervenham nelas revestidos de um poder de autoridade, mas em pé de igualdade com os particulares ${ }^{13}$.

Há uma divisão de águas essencial, mas elas podem dialogar, e até certo ponto misturar-se num tertium genus, "hoje há quem aponte uma divisão pluralista entendendo que certas matérias, de que seria exemplo típico o Direito Social, não cabem em nenhuma das duas categorias tradicionais". ${ }^{14} \mathrm{O}$ encontro das águas nem sempre se dá sem fusão, ainda que parcial e marginal.

\subsection{BREVE RELATO HISTÓRICO DA EVOLUÇÃO DO PÚBLICO E PRIVADO NO OCIDENTE}

Os primeiros registros da delimitação entre o público e privado no Ocidente teriam ocorrido na Grécia, cerca de 1.000 anos antes de Cristo. Neste período, o domínio privado era atinente ao domicílio e à família, e também ao predomínio da necessidade (carência e vontade), conforme aduz Moses Finley ${ }^{15}$. Dessa forma, o

\footnotetext{
${ }^{12}$ MACHADO, João Baptista. Introdução ao Direito e ao Discurso Legitimador. Almedina, 2016.p.65.

${ }^{13}$ MACHADO, João Baptista. Introdução ao Direito e ao Discurso Legitimador. Almedina, 2016. p. 65-66.

${ }^{14}$ MACHADO, João Baptista. Introdução ao Direito e ao Discurso Legitimador. Almedina, 2016. p. 66.

${ }^{15}$ FINLEY, Moses. "Introdução". In: FINLEY (Org.). O legado da Grécia: uma nova avaliação. Brasília: EdUnB, 1998.
} 
privado era considerado um fenômeno pré-político no qual se destacava a labuta e o trabalho e prevalecia a força e a violência. Já o público era o domínio da liberdade, também considerado o espaço de aparição onde ocorria a prevalência da ação e do discurso (palavras e persuasão).

Em Roma estabeleceu-se a diferença entre o direito público e o direito privado, que por sua vez levaram a instituição do direito romano, considerado a pedra fundamental de todo Direito Ocidental. A fórmula mais clássica é atribuída a Ulpiano: Publicum jus est quod ad statum rei romanae spectat, privatum, quod ad singulorum utilitatem.

No Direito Romano existia, pois, uma distinção (ou proto-distinção) entre direito público e direito privado; porém, não existia uma relação de continuidade entre ambas as coisas, pois ambos operavam como se fossem mundos à parte. Eventualmente, o direito privado determinava a interpretação do direito público, mas não o contrário, até mesmo por não existir entre eles o conceito de constitucionalismo e de hierarquia de normas como nós conhecemos. Atentemos no texto seguinte, nesse sentido:

A esfera privada compreendia o reino da necessidade, a atividade humana cujo objetivo era atender às exigências da condição animal no homem: alimentar-se, repousar, procriar etc. A necessidade coage o homem e obriga a exercer um tipo de atividade para sobreviver. Esta atividade é o labor. O labor distinguia-se do trabalho. Labor tinha a ver com o processo ininterrupto de produção de bens de consumo (alimento, por exemplo), isto é, aqueles bens que eram integrados no corpo após sua produção e que não tinham uma permanência no mundo: eram bens que pereciam. A produção destes bens exigia instrumentos que se confundiam com o próprio corpo [...] O lugar do labor era a casa [...] e a atividade correspondente constituía a economia [...]. A casa era a sede da família e as relações familiares eram baseadas nas diferenças: relação de comando e de obediência, donde a idéia do pater famílias, do pai, senhor de sua mulher, de seus filhos e de seus escravos. Isto constituía a esfera privada. A palavra privado tinha aqui o sentido de privus, do que é próprio, daquele âmbito em que o homem, submetido às necessidades da natureza, buscava sua utilidade no sentido de meios de sobrevivência. Neste espaço não havia liberdade, pois todos, inclusive o senhor, estavam 
sob a coação da necessidade. Libertar-se desta condição era privilégio de alguns: os cidadãos (cives). [...] O cidadão exercia sua atividade num outro âmbito: a polis, a cidade. Aí ele se encontrava entre os seus iguais. Sua atividade própria era a ação. [...] o terreno da ação era o do encontro dos homens livres, que se governam. Daí a idéia de ação política, dominada pela palavra, pelo discurso, pela busca dos critérios do bem governar, das normas do direito. A vida política constituía a esfera pública. Sendo das atividades, a mais característica do ser humano, a ação permitiu a idéia de animal político. ${ }^{16}$

Para os romanos, o público correspondia ao espaço da busca da excelência entre os iguais, no qual prevalecia a homogeneidade moral, política e a ausência de anonimato. Era a sociedade dos iguais, onde o poder poderia ser realmente exercido.

Preocuparam-se também os romanos em dividir o direito. A primeira classificação foi apresentada pelo jurisconsulto Ulpiano, que o separou em dois grandes ramos diferenciados pelo critério finalístico ou teleológico, isto é, pelo fim a que se destinam as normas de uma e de outra espécie. Ensina Ulpiano: 'Neste estudo, duas são as posições: a do público e a do privado. O direito público é o que diz respeito à organização do Estado romano; o privado é o que interessa aos particulares'. [...] Essa definição resultou dicotômica, também por influência de uma corrente filosófica grega, defendida por Heráclito e Próculo, segundo a qual tudo poderia ser explicado pelo princípio dos pares opostos em que se decompunha o absoluto, ou seja: se percebemos o frio, podemos conhecer o calor; se temos idéia do que é o mal, saberemos avaliar o bem; se obtivermos a noção do justo, poderemos identificar a justiça; e assim sucessivamente. De tal modo, dividindo-se o direito em duas partes contrárias, ficará mais fácil entendêlo e conceituá-lo, pois, em oposição, uma das partes levará naturalmente ao conhecimento da outra. ${ }^{17}$

A República de Roma entendia o privado como o ambiente onde se desenvolviam relações entre os que não eram cidadãos, como os comerciantes, as

${ }^{16}$ FERRAZ JÚNIOR, Tércio Sampaio. Introdução ao estudo do direito: técnica, decisão, dominação. São Paulo: Atlas, 1998. p. 127-128

${ }^{17}$ OLIVEIRA, Irineu de Souza. Programa de Direito Romano. Canoas-RS: ULBRA, 1998. p. 14. 
mulheres e os escravos. Era a sociedade dos desiguais. ${ }^{18}$

A idéia de apropriação individual, exclusiva e absoluta, de uma gleba de terra não é universal, nem histórica nem geograficamente. Ao contrário, é uma construção humana localizada e recente. Estado e Direito modernos começam a surgir na Europa lá por volta do século XIII, talvez antes, teorizados a partir do século XVI com as informações fantásticas que traziam de cada parte do mundo as caravelas dos aventureiros, conquistadores e mercadores. ${ }^{19}$

No século $\mathrm{XV}$, ocorre uma vaga de surgimento de Estados nacionais modernos (uns tantos tiveram o seu nascimento antes, mas não como Estados modernos, como é óbvio), nos quais prevalecia o exercício do poder pelo governante por meio de normas impostas aos cidadãos. Assim, ao contrário do período romano, o espaço público passa a ser onde ocorrem as relações entre os desiguais.

Os postulados do Estado Moderno, ou de Direito são os mesmos do direito privado, donde a conveniência de se focalizar, agora, o Estado Liberal de Direito. Suas principais características seriam: a) o primado da lei, no sentido de que todos os poderes derivam da lei, que é a realização da vontade popular. Todos os poderes dela derivam porque a lei prevê e regula comportamentos abstratos e gerais, válidos e obrigatórios para todos, sem distinção, e perante a lei, todos seriam iguais (igualdade formal); b) divisão de poderes, legislativo, executivo e judiciário, correspondentes a três momentos diversos do processo normativo: formação, aplicação e execução das leis. Tal separação representaria o resultado histórico da luta contra o absolutismo dos reis, em nome dos direitos do povo, de modo que só a vontade geral poderia produzir regras vinculantes para todos, por meio do Parlamento. Os juízes, não tendo investidura popular, não seriam representantes do povo, não teriam assim, poder legislativo. Seriam, apenas, a boca da lei e a sua decisão seria meramente silogística. E a própria administração pública, o Estado em si, não pode agir

\footnotetext{
${ }^{18}$ ROCHA, Cármem Lúcia Antunes. O princípio constitucional da Função Social da propriedade. In: BACELLAR FILHO, Romeu Felipe (coord.). Direito Administrativo Contemporâneo. Estudos em memória ao professor Manoel de Oliveira Franco Sobrinho. Belo Horizonte: Editora Fórum, 2004.

${ }^{19}$ MARÉS, Carlos Frederico. A função social da terra. Porto Alegre: Sérgio Antonio Fabris Editor, 2003. p.17.
} 
senão de modo conforme às leis. É o princípio da legalidade. c) Generalidade e abstração das regras jurídicas.A condição de aplicação das normas jurídicas compreenderia todas as pessoas da comunidade (generalidade), não apenas determinadas categorias sociais, e referir-se-ia a uma classe infinita de ações (abstração), adequadas à hipótese de aplicação, a chamada fattispecie; d) Distinção entre direito público e direito privado, entendendose aquele como 'o conjunto de normas com as quais o Estado determina a própria estrutura organizativa e regula as relações com os cidadãos', as normas de direito privado teriam a sua aplicação deixada à iniciativa individual, tendo assim o particular a disponibilidade do processo, o que é hoje o princípio dispositivo do processo civil. Além disso, as normas de direito privado destinar-se-iam à tutela dos interesses particulares, e não aos da coletividade; seriam dispositivas, no sentido de que permitiriam ao particular dispor como the aprouvesse, só se aplicando na falta de 'expressa vontade contrária dos interesses privados'. Seriam, também, derrogáveis. ${ }^{20}$

Portanto, o público era o local onde o governo especialmente "impunha" suas regulações aos governados. Houve também a consolidação (ou mesmo, segundo alguns, criação, ou criação moderna) do Estado, e essa consolidação naturalmente deu maior feição ao elemento público, e contraste com o privado, que se ateve cada vez mais, nesses tempos de modernidade nascente, à família e aos negócios, com o florescimento do mercado, que parte da Idade Média, com as suas dificuldades de contatos, transportes, e insegurança em parte havia feito esmorecer.

Os séculos XVII e XVIII correspondem a um período de apoteose do social, e muitas das atividades antes realizadas no confinamento do lar e da família passaram a ser feitas cada vez mais fora de casa. A esfera do trabalho se expande para além do domicílio e vai ganhar paulatinamente o espaço social, criando uma sociedade de trabalhadores e empregados, de classes organizadas e grupos políticos buscando a defesa de interesses coletivos. Neste período, o privado era relacionado ao domicílio, à família, à economia e aos contratos. Tudo isso consolida uma sociedade civil. Na interpretação de Amaral,

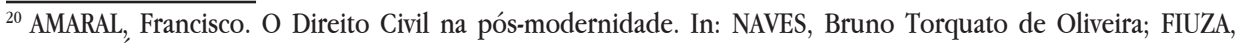
César; SÁ, Maria de Fátima Freire de. Direito Civil: atualidades. Belo Horizonte: Del Rey, 2003. p. 70-71. 
Nos ordenamentos jurídicos da época moderna (séc. XVIII e XIX) propriedade e liberdade são intimamente ligadas. A propriedade configura-se, assim, como um poder pleno e exclusivo do proprietário, e como um princípio da organização política e econômica da sociedade liberal. À propriedade privada cabe, por isso, o papel de princípio organizativo das relações econômicas e sociais, que está na base da sociedade moderna gerada pela Revolução Francesa. Consequentemente, existe profunda conexão entre propriedade, empresa e mercado. ${ }^{21}$

Enquanto o público dizia respeito à corte, à esfera de autoridade pública e à administração pública do governo e do Estado, também as atividades relacionadas à produção e à sobrevivência se libertam do confinamento dos domicílios e tornam-se, relevantes "publicamente".

Um aspecto importante deste tempo e que vai como que anunciando já o futuro surgimento da sociedade da informação, foi a crescente troca no nível da informação, precipitada pela ascensão do jornal impresso e outros periódicos.

Ulteriormente, no século XIX, nos países que conheceram a revolução industrial nasceu o capitalismo liberal, que no plano filosófico-político se centraria nos polos: indivíduo - sociedade - Estado, como sustenta Rogério Ehrhart Soares ${ }^{22}$. Assim, com a crise vivida pelo capitalismo e que culminou com a grande depressão econômica mundial vivida a partir de 1929, a atuação do Estado na produção de bens públicos, sejam produtos ou serviços, se intensificou, através do New Deal (Novo Acordo/ série de programas implementados nos EUA para recuperar a economia) de Franlkin Delano Roosevelt, a fim de garantir o wellfair (bem-estar) da população e criar condições para a diminuição do desemprego, ação que o liberalismo muito dificilmente conseguiria realizar, e assim criou a economia social de mercado que é irmã gêmea do Estado Social, o qual se entenda, nada tem a ver com o Estado providência, o dito "Estado-patrão", do "Capitalismo de Estado", a que, alguns chamam "socialismo". ${ }^{23}$

Já no século XX, ocorreram momentos decisivos e agudos de uma oposição

\footnotetext{
${ }^{21}$ AMARAL, Francisco. Direito Civil: Introdução. 5 ed. São Paulo: Renovar, 2003. p. 146.

${ }^{22}$ SOARES, Rogério Ehrhardt. Direito Público e Sociedade Técnica, Coimbra, Ed. Biblioteca Jurídica, Atlântida, 1969.

${ }^{23}$ CUNHA, Paulo Ferreira da. Direito Constitucional Geral: uma Perspectiva Luso-Brasileira. São Paulo: Método, 2007.p. 237.
} 
travada entre o Estado (público) e a sociedade civil (privado). Alguns deles, porém, empolados e com uma imagética artificial. Porquanto o que parecia ser privatista nem sempre se apoiava inteiramente e apenas em forças privadas, por exemplo. Esta é a síntese de Maria Celina B. Moraes, que merece ser ponderada.

Defronte de tantas alterações, direito privado e direito público tiveram modificados seus significados originários: 0 direito privado deixou de ser o âmbito da vontade individual e o direito público não mais se inspira na subordinação do cidadão. A divisão do direito, então, não pode permanecer ancorada àqueles antigos conceitos e, de substancial - isto é, expressão de duas realidades herméticas e opostas traduzidas pelo binômio autoridade - liberdade - se transforma em distinção meramente 'quantitativa': há institutos onde é prevalente o interesse dos indivíduos, estando presente, contudo, o interesse da coletividade; e institutos em que prevalece, em termos quantitativos, o interesse da sociedade, embora sempre funcionalizado, em sua essência, à realização dos interesses individuais e existenciais dos cidadãos. Mais: no Estado Democrático de Direito, delineado pela Constituição de 1988, que tem entre seus fundamentos a dignidade da pessoa humana e os valores sociais do trabalho e da livre iniciativa, o antagonismo público-privado perdeu definitivamente o sentido. Os objetivos constitucionais de construção de uma sociedade livre, justa e solidária e de erradicação da pobreza colocaram a pessoa humana - isto é, os valores existenciais no vértice do ordenamento jurídico brasileiro, de modo que tal é o valor que conforma todos os ramos do Direito. ${ }^{24}$

No mundo moderno, teríamos uma completa evolução da esfera privada, com a aproximação entre o social e o político, de forma a gerar a "sociedade" onde os interesses privados adquirem importância pública. Houve ainda, deve recordarse, a ascensão à esfera pública do modelo administrativo e das atividades reservadas à casa e à família. Tal provoca enormes transformações nessas esferas, além de diluir a divisão entre elas.

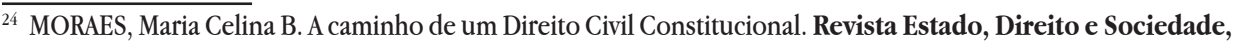
São Paulo, v. 1, jul./set. 1991, publicação do Departamento de Ciências Jurídicas da PUC/RJ. Disponível em: www.idcivil.com.br/pdf/biblioteca4.pdf. Acesso em: 10. 12. 2016. p. 4 


\section{OS IMPACTOS DA SOCIEDADE DA INFORMAÇÃO NO DIREITO}

Em 1969, com a criação da Arpanet nos EUA, houve o início do desenvolvimento tecnológico na área da comunicação por computadores, bem como a criação de jogos visando capacitar os agentes militares. Na verdade, porém, as universidades norte-americanas já utilizavam mecanismos de comunicação que hoje conhecemos por internet.

O sociólogo Daniel Bell, em 1973, manifesta a ideia de sociedade da informação, que consiste na interação e na circulação de conhecimento por meio das relações humanas. ${ }^{25}$ Em 1980, a sociedade da informação começou a ser popularizada. No final da década 80 , surge a ideia da criação das condutas que viriam implantar o que é a sociedade da informação, a inclusão digital e a interação através da internet.

No Brasil, o Ministério da Ciência e Tecnologia do governo federal elaborou, em 1997, o Livro Verde da Sociedade da Informação, que constitui um documento que visa implantar e promover a facilitação de acesso à comunicação pela via virtual. Esse livro tem como características efetivar normas de orientação.

A tecnologia da informação é para esta revolução o que as novas fontes de energia foram para as Revoluções Industriais sucessivas, do motor a vapor à eletricidade, aos combustíveis fósseis e até mesmo à energia nuclear, visto que a geração e distribuição de energia foi o elemento principal na base da sociedade industrial. ${ }^{26}$

Assim, existe o entendimento de que está em andamento uma revolução da sociedade da informação.

[...] as instituições, as companhias e a sociedade em geral transformam a tecnologia, qualquer tecnologia, apropriando-a, modificando-a, experimentando-a [...] esta é a lição que a história social da tecnologia ensina [...] A comunicação

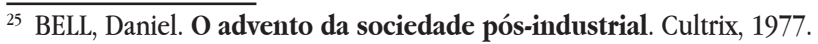

${ }^{26}$ CASTELLS, Manuel. A Era da Informação: economia, Sociedade e Cultura. A Sociedade em Rede. Vol. 1. São Paulo: Paz e Terra, 1999. p. 50
} 
consciente (linguagem humana) é o que faz a especificidade biológica da espécie humana. Como nossa prática é baseada na comunicação, e a Internet transforma o modo como nos comunicamos, nossas vidas são profundamente afetadas por essa nova tecnologia da comunicação. ${ }^{27}$

A tecnologia da informação é para esta revolução o que as novas fontes de energia foram para as revoluções industriais sucessivas, do motor a vapor à eletricidade, aos combustíveis fósseis e até mesmo à energia nuclear, visto que a geração e distribuição de energia foi o elemento principal na base da sociedade industrial. ${ }^{28} \mathrm{~A}$ aludida revolução altera de forma mais acentuada a forma de se comunicar da sociedade, conforme explica Kaminski:

[...] um novo ambiente humano e tecnológico de expressão, informação e transações econômicas. Consiste em pessoas de todos os países, de todas as culturas e linguagens, de todas as idades e profissões fornecendo e requisitando informações; uma rede mundial de computadores interconectada pela infraestrutura de telecomunicações que permite à informação em trânsito ser processada e transmitida digitalmente. ${ }^{29}$

Portanto, a sociedade da informação é, além do mais, uma ideia-força e um slogan, uma expressão que traz a ideia da importância de receber uma informação. Muito embora tenha um conteúdo sociológico, a expressão sociedade da informação possui um impacto na esfera jurídica dos indivíduos, isto porque estamos frequentemente tratando dos direitos atrelados à informação.

[...] um novo ambiente humano e tecnológico de expressão, informação e transações econômicas. Consiste em pessoas de todos os países, de todas as culturas e linguagens, de todas as idades e profissões fornecendo e requisitando informações; uma rede mundial de computadores interconectada pela infraestrutura de telecomunicações que permite à informação

\footnotetext{
${ }^{27}$ CASTELLS, Manuel. A galáxia da Internet: reflexões sobre a Internet, os negócios e a sociedade. Rio de Janeiro: J. Zahar, 2003. p. 10

${ }^{28}$ CASTELLS, Manuel. A Era da Informação: Economia, Sociedade e Cultura. A Sociedade em Rede. Vol. 1. São Paulo: Paz e Terra, 1999.

${ }^{29}$ KAMINSKI, Omar. (Org.). Internet Legal: o Direito na tecnologia da informação: Doutrina e Jurisprudência. Curitiba: Juruá, 2005. p. 40.
} 
em trânsito ser processada e transmitida digitalmente..$^{30}$

O desenvolvimento das estruturas tecnológicas muda constantemente em tempo dinâmico, acarretando alterações em praticamente todos os aspectos da vida em sociedade, conforme observa Castells.

[...] as instituições, as companhias e a sociedade em geral transformam a tecnologia, qualquer tecnologia, apropriando-a, modificando-a, experimentando-a [..] esta é a lição que a história social da tecnologia ensina [...] A comunicação consciente (linguagem humana) é o que faz a especificidade biológica da espécie humana. Como nossa prática é baseada na comunicação, e a Internet transforma o modo como nos comunicamos, nossas vidas são profundamente afetadas por essa nova tecnologia da comunicação. ${ }^{31}$

A influência do desenvolvimento dessas estruturas tecnológicas no direito pode ser visualizada na sua utilização nos procedimentos judiciais como, por exemplo, as plataformas cíveis e trabalhistas de peticionamento e de acompanhamento processual, tais como o e-saj e o pje.

Com o uso cada vez maior de TICs (tecnologias da informação e comunicação), redesenham-se as formas de vida e trabalho, impondo um novo ritmo ao desenvolvimento das atividades humanas. Seu funcionamento implica na necessidade de redefinição de tempo e espaço, resultando, dentre outros fatores, em novos processos na organização e desenvolvimento do trabalho pelo ciberespaço como, por exemplo, o teletrabalho.

Por sua vez, tem grande impacto no direito do trabalho, dado que relativiza alguns dos requisitos fundamentais para a configuração do vínculo empregatício, como a subordinação e a pessoalidade. Os meios de trabalho, que em alguns casos eram pedra de toque da relação laboral (sendo pertença do empregador) passam frequentemente a ser propriedade do trabalhador, que em algumas sociedades passa a ser prestador de serviços ou a empregado que se vai rebaixando sutilmente como "colaborador", apesar de em certas circunstâncias ainda manter o seu estatuto laboral clássico. Não se sabe até quando, porquanto mesmo empregos públicos se

\footnotetext{
${ }^{30}$ KAMINSKI, Omar. (Org.). Internet Legal: o Direito na tecnologia da informação: Doutrina e Jurisprudência. Curitiba: Juruá, 2005. p. 40.

${ }^{31}$ CASTELLS, Manuel. A galáxia da Internet: reflexões sobre a Internet, os negócios e a sociedade. Rio de Janeiro: J. Zahar, 2003. p. 10.
} 
"privatizam".

Aquela relativização ocorre, nomeadamente, porque o teletrabalhador não precisa mais se deslocar ao trabalho para realizar sua função. A partir desta mudança de comportamento surgem questões de controle de horário e de verificação de ser mesmo a pessoa contratada que está executando o trabalho remoto.

Assim como aconteceu com grandes invenções, a Internet passou a ser utilizada, também, para o cometimento de crimes. Os crimes da Internet, também denominados crimes da era digital, ou ainda, cibercrimes, vem se alastrando no mundo. É indubitável que a Internet modificou o comportamento humano. Pois, de um lado, incentivou a busca de novos conhecimentos e a expansão da cultura, por outro lado, também propiciou o surgimento dos crimes digitais. ${ }^{32}$

Outro importante impacto a ser considerado é na esfera do direito penal. Sob esta ótica, o direito se insere em um aspecto negativo do desenvolvimento da tecnologia da informação, na medida em que deva atuar para coibir ou diminuir sensivelmente o uso de tal ferramenta para fins antiéticos, o que poderá caber no âmbito do direito penal (nem sempre, porque, como se sabe, e para além do seu caráter subsidiário, non omne quod licet honestum est). Para isso, segundo Gois Júnior,

[...] é preciso introduzir meios de regulamentação ética na rede, até mesmo porque já se passou o período romântico e idealista no qual a internet era concebida apenas como um imenso repositório de informação e cultura, templo de intelectuais e acadêmicos de vanguarda, para um outro em que ela, a cada dia, se transforma em mais um instrumento da sociedade de consumo. ${ }^{33}$

Além disso, acerca dos impactos temos a influência do desenvolvimento da informática sob a privacidade, alterando seu conceito que, a partir dos anos 80, passou a corresponder ao direito que toda pessoa tem de dispor com exclusividade

$\overline{32}$ INELLAS, Gabriel Cesar Zacarias. Crimes na internet. São Paulo: Juarez de Oliveira Ltda, 2004. p. 09

${ }^{33}$ GOIS JUNIOR, José Caldas. O direito na era das redes: a liberdade e o delito no ciberespaço. Bauru: EDIPRO, 2001. p. 30 
sobre as próprias informações mesmo quando disponíveis em banco de dados. ${ }^{34}$

Portanto, pode-se notar que a sociedade da informação tem grande impacto em vários ramos do direito. Alguns citados nesse item foram o penal, o cível, o trabalhista e o constitucional, porém as será complicado encontrar algum que não tenha sofrido as mudanças.

\section{AS TRANSFORMAÇÕES DA MAGNA DIVISIO PÚBLICO/PRIVADO NA SOCIEDADE DA INFORMAÇÃO}

O Estado, como realidade social, está também incluído na categoria de sociedade; ele é uma comunidade, ele faz parte do todo social. Evidentemente que há vários sentidos da palavra Estado. Mas nunca se considerará um Estado totalmente avesso à sociedade senão numa perspetiva de contraste ideológico. E, portanto, gerador potencial ao menos de polêmica.

$\mathrm{O}$ direito visto de uma perspectiva normativista (embora muitas mais existam) está incluído na categoria de sistema de normas: ele é um sistema de normas, uma ordem normativa. Estado e direito, segundo essa visão, são dois objetos diferentes. A dualidade de Estado e direito é, na verdade, um dos fundamentos da ciência política e da jurisprudência moderna. ${ }^{35}$ Embora, evidentemente, nem sempre querendo-se separar tal se consiga cabalmente [...] Kelsen é um caso disso mesmo [...]. A concepção oitocentista de Código Civil supunha que este era capaz de prever todas as situações pelas quais passaria o indivíduo no curso de sua vida: nascimento, maioridade civil, realização de negócios, aquisição da propriedade, casamento, morte. Nesse sentido, a organização do código, particularmente, do Código de Napoleão, correspondia ao movimento natural deste indivíduo, sem buscar necessariamente um rigor lógico ou o estabelecimento de uma ordenação perfeitamente dedutiva entre os seus artigos. ${ }^{36} \mathrm{O}$ código português do Visconde de Seabra era um decalque ou projeção jurídica da trilha de vida da pessoa.

A concepção do modelo jurídico de codificação enquanto sistema fechado,

\footnotetext{
${ }^{34}$ PAESANI, Liliana Minardi. Direito e Internet: liberdade de informação, privacidade e responsabilidade civil. São Paulo: Atlas, 2012.

35 KELSEN, Hans. Teoria Pura do Direito. 7. ed. Tradução de João Baptista Machado. São Paulo: Martins Fontes, 2006.

36 PREDIGER, Carin. A noção de sistema no direito privado e o código civil como eixo Central In: COSTA, Judith Martins. (Org.). A reconstrução do Direito Privado. São Paulo: Editora Revista dos Tribunais, 2002.
} 
embasada numa visão totalizadora, que antes assegurava o "mundo da segurança", não mais se apresenta suficiente diante do surgimento de uma multiplicidade de leis especiais, destinadas a abarcar as novas relações jurídicas e os novos campos emergentes do direito. Há a perda de centralidade do código, porquanto este passa a dividir o papel que antes lhe incumbia com uma série de leis, que, mais do que "esparsas", muitas vezes se constituem verdadeiros microssistemas e subsistemas..$^{37}$

Como norma que presume prender a complexidade do social em um sistema fechado, o Código, toda a codificação, somente pode traduzir-se em uma operação drasticamente redutiva: se a razão civil pode e deve desenhar-se em uma harmonia geométrica, sob a égide da máxima simplicidade e da máxima clareza, o legislador deve empenhar-se em um esforço de depuração e decantação. ${ }^{38}$ Contudo, o Código é um enorme progresso da técnica jurídica e da liberdade. A multiplicidade normativa, mesmo com os computadores em auxílio de todos, corresponde a uma selva de regras e contrarregras. Apenas uma reinvenção da codificação poderá dar sentido ao direito futuro. Sem as pretenções excessivas dos primeiros entusiasmos, naturalmente.

O Estado Contemporâneo, também denominado Estado constitucional ${ }^{39}$, não deverá ser caracterizado por uma relação de supra/infraordenação entre cidadão e Estado, onde um é subordinado ao poder, à "soberania" (ou ao que dela reste) e, por vezes, ao arbítrio do outro, mas por um compromisso constitucionalmente garantido de realizar o interesse de cada pessoa no contexto do interesse comum. A Constituição deixou de ser somente política, mas da sociedade. A grande tarefa do Estado, assim, não é tanto de impor aos cidadãos um próprio interesse superior, quanto de realizar a tutela dos direitos fundamentais e de favorecer o pleno desenvolvimento da pessoa (que tem consagração constitucional explícita na Alemanha), removendo os obstáculos que impedem a participação de todos na vida do Estado, e fomentando essa participação. ${ }^{40} \mathrm{~A}$ partir dessa ideia, surge o governo eletrônico (e-gov). Portanto, Segundo Aires J. Rover,

Governo eletrônico é uma infra-estrutura única de

\footnotetext{
${ }_{37}$ PREDIGER, Carin. A noção de sistema no direito privado e o código civil como eixo Central In: COSTA, Judith Martins- (org.). A reconstrução do Direito Privado. São Paulo: Editora Revista dos Tribunais, 2002.

${ }^{38}$ GROSSI, Paolo. Mitologias jurídicas da modernidade. 2 ed. .Florianópolis: Fundação Boitex, 2007.

${ }^{39}$ HAEBERLE, Peter. El Estado Constitucional. Estudo introdutório de Diego Valadés, trad. e índices de Héctor Fix-Fierro. México : Universidad Nacional Autónoma de México, 2003.

${ }^{40}$ PERLINGIERI, Pietro. Perfis do Direito Civil: Introdução ao Direito Civil Constitucional. 2. ed. Tradução de Maria Cristina De Cicco. Rio de Janeiro: Renovar, 2002.
} 
comunicação compartilhada por diferentes órgãos públicos a partir da qual a tecnologia da informação e da comunicação é usada de forma intensiva para melhorar a gestão pública e o atendimento ao cidadão. Assim, o seu objetivo é colocar o governo ao alcance de todos, ampliando a transparências das suas ações e incrementando a participação cidadã ${ }^{41}$

O governo eletrônico é uma maneira de promover a administração das funções do Estado (Poder Executivo, Poder Legislativo e Poder Judiciário) e de persecução dos objetivos estabelecidos ao Estado democrático de Direito, que usa as novas tecnologias da informação e comunicação como ferramenta de interação com os cidadãos e de prestação dos serviços públicos. Evidentemente que pode haver mau uso, uso perverso, destes meios. Mas é a sina de qualquer técnica. Aires Rover salienta que

O governo eletrônico é uma forma de organização do conhecimento que permitirá que muitos atos e estruturas meramente burocráticas simplesmente desapareçam e a execução de tarefas que exijam uma atividade humana mais complexa seja facilitada. ${ }^{42}$

O governo eletrônico pode ser dividido em três categorias: $G 2 G$, que envolve compras ou transações entre governos; G2B caracterizado pela relação entre governo e fornecedores e $\mathrm{G} 2 \mathrm{C}$, relação entre governo e cidadãos. As duas primeiras categorias ainda são as responsáveis pela maior parte dos investimentos feitos.

Há, porém outras visões sobre o governo eletrônico, governação eletrônica e governança (governance) eletrônica. Com menos especificidades técnicas, o que alguns temem na utilização excessiva e pseudodemocrática dos meios informáticos e afins é uma forma totalitária e plebiscitária populista, em que embora cada um possa decidir aparentemente e condicionado pelo marketing e a lavagem cerebral da propaganda de coisas menores, as grandes decisões possam realmente ser as do "Grande Irmão". Muito eloquente é o clássico de tirinhas de Edgar P. Jacobs Le piège diabolique, na parte do futuro, um futuro de sociedade totalitária da informação. ${ }^{43}$

\footnotetext{
${ }^{41}$ ROVER, Aires José, Governo eletrônico: uma introdução. 2012. Disponível em: http://www.egov.ufsc.br/ portal/conteudo/texto-governo-eletr\%C3\%B4nico-uma-introdu\%C3\%A7\%C3\%A3o. Acesso em: 27/09/2016.

${ }^{42}$ ROVER, Aires José. (Org.). Direito e Informática. SP: Manole, 2004. p. 12

${ }^{43}$ JACOBS, Edgar P. Le piège diabolique. Trad. Port. de Paula Caetano. A Armadilha Diabólica. Porto: Asa, 2008.p. 26 ss.
} 
Em suma, parece não fazer sentido, nos tempos atuais, falar-se na permanência de uma real, essencialista, ontológica "dicotomia" entre direito público e direito privado, entendida a mesma na forma determinada por Bobbio, como duas esferas reciprocamente opostas, excludentes e exaustivas. Talvez se possa, no máximo, manter a idéia de uma mera "distinção" que se fragiliza ou deve pelo menos flexibilizar diante de determinadas situações impostas pela nova ótica de refundação das bases do direito privado em face da Constituição. ${ }^{44}$

De outro ponto de vista, o direito privado (como todo o direito) é direito constitucional aplicado, pois nele se detecta o projeto de vida em comum que a Constituição tem em vista; o direito privado representa os valores sociais de vigência efetiva. Por isso é que o direito privado se vê modificado por normas constitucionais.

As novas tecnologias de comunicação e informação imprimem novas marcas ao espaço público, criando assim a denominada Era da Sociedade da Informação. $\mathrm{O}$ direito propriamente dito, depois doJus redigere in artem, sempre esteve ligado ao desenvolvimento das cidades. Estas estão a mudar de feição. Impossível que o direito e as suas divisões não reflitam essas transformações.

As cidades não podem ser conceituadas apenas como aglomeração de pessoas em uma localidade, pois surgiram as cidades digitais, as cidades da globalização, onde as redes telemáticas fazem parte do dia a dia e constituem-se como a infraestrutura básica e hegemônica da época, fazendo a interligação entre cidadãos e entre esses e o Poder Público. Porém, não é fácil entender esta nova realidade, sendo de ter cuidado com o mito da desterritorialização, que pode redundar em ilusões perigosas. ${ }^{45} \mathrm{O}$ território físico, geográfico, ainda é uma das principais razões de conflito e guerra, por exemplo. ${ }^{46}$

Celso Antonio Pacheco Fiorillo entende que em pleno século XXI as cidades podem assumir uma nova faceta, não mais a da conceituação clássica de território, mas a de "território digital" capaz de interligar 500 milhões de habitantes. ${ }^{47}$

De acordo com André Lemos, o termo Cidade Digital (ou Cibercidade) pode ser dividido em quatro espécies que relacionam cidades e novas tecnologias de comunicação. Primeiramente, entende-se que Cidades Digitais são os

\footnotetext{
${ }_{44}$ SILVEIRA, Michele Costa da. As grandes metáforas da bipolaridade. In: COSTA, Judith Martins. (Org.). A reconstrução do direito privado. São Paulo: Editora Revista dos Tribunais, 2002.

${ }^{45}$ HAESBAERT, Rogério. O Mito da Desterritorialização. 2. ed., Rio de Janeiro: Bertrand Brasil, 2006.

${ }^{46}$ CUNHA, Paulo Ferreira da. Direito Internacional. Raízes \& Asas. Prefácio de Marcílio Toscano Franca Filho, Posfácio de Sérgio Ricardo Fernandes de Aquino. Belo Horizonte: Forum, 2017. p. 107 ss., p. 203 ss.

${ }^{47}$ FIORILlO, Celso Antonio Pacheco. O Direito da Antena em Face do Direito Ambiental no Brasil, Ed. Fiúza, 2009.
} 
[...] projetos governamentais, privados e/ou da sociedade civil que visam criar uma representação na web de um determinado lugar. Cidade Digital é aqui um portal com informações gerais e serviços, comunidades virtuais e representação política sobre uma determinada área urbana. Um dos projetos pioneiros foi De Digitale Stad, da cidade de Amsterdã, criado em 1994 por uma organização civil hoje transformada em entidade de utilidade pública. ${ }^{48}$

A segunda espécie de Cidade Digital pode ser a denominada Cidade Inteligente, que se constitui na criação de infraestrutura, serviços e acesso público em uma determinada área urbana para que os habitantes façam uso das novas tecnologias e redes telemáticas. O objetivo é criar conexões entre o espaço eletrônico e o espaço físico pelo oferecimento de teleportos, telecentros, quiosques multimídias e áreas de acesso e serviços. Resultando, por exemplo, na criação de espaços públicos com conexão Wi-Fi gratuita, que, juntamente com os smartphones, mudaram a maneira como a maioria das pessoas se comunica, o que é de suma importância, pois um dos grandes aspectos que diferenciam os homens dos animais é a maneira como os homens se comunicam, conforme leciona Flusser.

A comunicação humana é um processo artificial. Baseia-se em artifícios, descobertas, ferramentas e instrumentos, a saber, em símbolos organizados em códigos. Os homens comunicam-se uns com os outros de uma maneira não "natural": na fala não são produzidos sons naturais, como, por exemplo, no canto dos pássaros, e a escrita não é um gesto natural como a dança das abelhas. Por isso, a teoria da comunicação não é uma ciência natural, mas pertence àquelas disciplinas relacionadas com os aspectos não naturais do homem, que já foram conhecidos como "ciência dos espíritos" (Geiteswissenschaften). ${ }^{49}$

O terceiro tipo de Cidade Digital refere-se a modelagens 3D a partir de Sistemas de Informação Espacial (SIS, spacial information system e GIS, geographic information system) para criação de simulação de espaços urbanos. Esses modelos são denominados de CyberCity SIS e são sistemas informatizados utilizados

\footnotetext{
${ }_{48}$ LEMOS, André. Cibercidade: As cidades na cibercultura. Editora E-papers, 2004. p. 12.

${ }^{49}$ FLUSSER, Vílem. Lingua e Realidade. 3 ed. São Paulo: Annablume, 2007. p. 89.
} 
para visualizar e processar dados espaciais de cidades. As simulações ajudam no planejamento e gestão do espaço, servindo como instrumento estratégico do urbanismo contemporâneo.

A quarta categoria, que podemos denominar de "metafórica", é formada por projetos que representam uma cidade virtual, não baseada em cidades reais, que via de regra servem de plataformas para jogos de computador e de videogame. Segundo Lemos,

Estes projetos são chamados por alguns autores de nongrounded cybercities, cidades não enraizadas em espaços urbanos reais. Essas Cidades Digitais são sites que criam comunidades virtuais (fóruns, chats, news, etc.) utilizando a metáfora de uma cidade para a organização do acesso e da navegação pelas informações. Nesse caso, não há uma cidade real, como, por exemplo, Twin Worlds, V-Chat, DigitalEE ou o popular Second Life. ${ }^{50}$

O direito público causou impactos no espaço particular. Um deles é denominada constitucionalização do direito privado, que consiste numa expressão utilizada para referir-se ao processo de transformação ou de mudança de paradigma que a relação entre o direito constitucional e o direito privado passou a sofrer com o constitucionalismo e, mais especificamente, com a democracia constitucional.

A promoção da democracia no domínio público foi de início, primordialmente um projeto masculino - do qual as mulheres afinal conseguiram participar, sobretudo através de sua própria luta. A democratização da vida pessoal é um processo menos visível, em parte justamente por não ocorrer na área pública, mas suas implicações são também muito profundas. ${ }^{51}$

As novas tecnologias como, por exemplo, as câmeras, fizeram do espaço público uma extensão do espaço privado, na medida em que a imagem das pessoas, que antes permanecia, via de regra, sob o domínio da pessoa, agora é praticamente de domínio público, pois não se pode mais controlar quando e por quem se vai ser filmado. Mas, pode ver-se a questão por outro prisma: todo privado parece tender

${ }^{51}$ GIDDENS, Anthony. A transformação na intimidade. São Paulo:UNESP, 1993.p. 201. 
para público, porque tudo é publicizado, e eventualmente publicado. As redes sociais são um exemplo de algum exibicionismo por parte de simples particulares.

Ademais, o espaço público se tornou uma continuidade do espaço privado, na medida em que, por exemplo, a pessoa pode acessar a internet via Wi-Fi em diversas praças e espaços públicos de cidades, coisa que antes só poderia fazer em sua residência.

Assim, pode-se inferir que as transformações na dicotomia entre o público e o privado na sociedade da informação se deram tanto no direito como nos espaços públicos e privados, alterando significativamente vários aspectos da vida em sociedade.

\section{CONCLUSÃO}

Os aspectos da sociedade da informação evidenciam um impacto da tecnologia no direito e reflexos da informação no espaço público e particular das sociedades. A abordagem realizada evidencia a tecnologia, a informação e a forma como impactaram no direito e na geração de uma nova era.

A sociedade da informação por meio do desenvolvimento tecnológico trouxe aplicativos para auxílio à mobilidade urbana, redes sociais, e-gov, mecanismos de votação eletrônica, métodos alternativos de exercício da democracia por meio da tecnologia etc.

Há uma tendência para embandeirar em arco relativamente a todas estas novidades, mas elas deveriam ser ponderadas e escrutinadas com muita prudência, porque a verdade é que o cidadão comum já vai sentido no quotidiano, em relação a gadgets relativamente inócuos à partida, o que é o fim da sua privacidade, do seu sossego, mesmo do seu horário de trabalho. E ainda estamos no início da aplicação das grandes novas invenções ao dia a dia. E ainda se trata, em grande medida, de servidão e submissão voluntárias. Como será o mundo quando os empregadores ou o próprio Estado a todos obrigar a usar este ou aquele aplicativo? Aparentemente, no início tudo é excelente... Mas... e depois?

O desaparecimento ou a atenuação dos limites geográficos, o pluralismo 
jurídico, a internacionalização dos direitos humanos, análise econômica do direito na tomada de decisões, são áreas afetadas diretamente pela sociedade da informação. Todas estas realidades e vetores têm cunho ideológico. Houve já quem explicitasse, por exemplo, como os direitos humanos se opõem radicalmente às perspectivas economicistas, como é o caso do embaixador José Augusto Lindgren Alves, que afirma que o "direito à segurança, os direitos civis e políticos também requerem investimentos vultosos por parte do Estado, no controle de seus agentes"52, fazendo com que a tutela dos direitos humanos, do ponto de vista dos economicistas, não seja assim tão interessante. Aliás, o mesmo autor denuncia a esquizofrenia internacional que de um lado proclama os direitos humanos e o solidarismo e do outro se baseia num economicismo muito simplista. ${ }^{53}$

No crescimento paulatino das sociedades, a informação foi pulverizada e seu alcance aumentou o acesso, fazendo com que de certo modo crescesse e incluísse, muito embora ainda existam milhões de excluídos. A possibilidade de ser informado e de conhecer estabeleceu a possibilidade de que o pensamento voltado às minorias estigmatizadas e seus sistemas jurídicos de organização pudessem ser reconhecidos.

A ruptura das fronteiras por meio da economia globalizada possibilitou que o direito de proteção à humanidade e os seus bens desafiassem os míticos critérios de soberania (em grande medida ilusórios e defasados: pois Bodin e Hobbes pensavam noutros contextos e objetos). ${ }^{54}$

A sociedade da informação ensejou ainda uma reflexão sobre o isolamento boc sensu (não o Isolierung) do direito. A qual está longe de terminada.

Não se concebe mais o espaço público tão somente como um espaço político e o direito privado atinente a relações entre particular; a sociedade da informação é um pano de fundo que propicia ligações para estas mudanças nas estruturas jurídicas.

Podemos enxergar o ambiente de sociedade da informação de duas maneirais.

A primeira seria o de preponderância da informação como fator propulsor do desenvolvimento das tecnologias e, por conseguinte, sua função como agente principal da alteração do modo como as comunicações se estabelecem. A segunda

\footnotetext{
${ }_{52}$ ALVES, José Augusto Lindgren. A Arquitetura Internacional dos Direitos Humanos. Editora FTD, 1997.

${ }^{53}$ ALVES, José Augusto Lindgren. A Arquitetura Internacional dos Direitos Humanos. Editora FTD, 1997.

${ }^{54}$ CUNHA, Paulo Ferreira da. Direito Internacional. Raízes \& Asas. Prefácio de Marcílio Toscano Franca Filho, Posfácio de Sérgio Ricardo Fernandes de Aquino. Belo Horizonte: Forum, 2017. p. 93 ss.
} 
seria o de constituir uma nova Era, pois, assim como existiu a Era industrial, fruto das revoluções industriais, hoje existe a Era da (sociedade) informação, decorrência de uma revolução da informação, e principalmente da comunicação, que pode ser rastreada dos primórdios do desenvolvimento da imprensa (máquina) até a efetiva implementação da internet para a maioria da coletividade.

Dessa forma, a sociedade da informação influenciou e interferiu sobremaneira no espaço público e privado, fazendo com que sua delimitação se tornasse fugaz, praticamente inexistente. Pelo menos árdua. Contudo, é necessário problematizar até que ponto isso é positivo, e se não deve haver um reduto para o privado no mundo futuro.

Portanto, pode-se concluir que a sociedade da informação interferiu na concepção clássica da divisão entre espaço público e o privado e serviu para diluir e, quiçá, vir um dia a acabar com a delimitação entre aludidos espaços, e assim, consequentemente, tal interferência refletiu no direito, fazendo com que novas regulações como, por exemplo, o marco civil da internet, e novas formas de uso das tecnologias alterassem a forma como o direito contemporâneo interage com as sociedades, fazendo, por exemplo, com que os meios de peticionamento, acompanhamento e condução dos processos mudasse radicalmente a maneira de operar o direito.

É evidemente que não é provável que nenhum cataclismo cósmico venha a fazer regredir a humanidade para uma sociedade pré-informacional. A grande questão, neste tema, é se saberemos usar bem as tecnologias que nos são facultadas. É de suspeitar que governos, poderosas entidades privadas e afins, na posse desses instrumentos, não propriamente os publicizem, mas os privatizem em seu proveito próprio. E esse é o grande, o maior dos perigos. Instrumentalizando o próprio direito nesse sentido.

Na verdade, a questão obriga a pensar no público e no privado de uma forma mais plural e com várias possibilidades. Pode haver o sagrado limite da privacidade sagrada do cidadão, e a esse limite deve estar sempre o direito de vigilante guarda, e, por outro lado, um privatismo egoísta, que não só avance sobre o público como não respeite o privado dos outros. Do mesmo modo, pode haver um publicismo saudável, que governa e promove o bem comum, e esse sempre o direito (em busca da Justiça) tem de defender, mas também pode haver um totalitário publicismo que, tudo expondo ou tudo invadindo, transforme o cidadão em pária, ou em robô. Esse 
publicismo não pode ser consentido pelo direito.

Ao ficarem oscilantes as fronteiras entre público e privado, mais se agudiza a necessidade de publicistas ou privatistas de formação, os juristas exerçam uma esperta vigilância sobre as tentações egoístas e as tentações coletivistas.

\section{REFERÊNCIAS}

ALVES, José Augusto Lindgren. A Arquitetura Internacional dos Direitos Humanos. [s.l.]: FTD, 1997.

AMARAL, Francisco. Direito Civil: Introdução. 5. ed. São Paulo: Renovar, 2003.

AMARAL, Francisco. O Direito Civil na pós-modernidade. In: NAVES, Bruno Torquato de Oliveira; FIUZA, César; SÁ, Maria de Fátima Freire de. Direito Civil: atualidades. Belo Horizonte: Del Rey, 2003.

ARENDT, Hannah. A condição humana. 10. ed. Tradução de Roberto Raposo. Rio de Janeiro: Forense Universitária, 2003.

BARROS, Gilda Naécia Maciel. Agraphoi Nomoi. Disponível em: http://www. hottopos.com/notand3/agrafoi.htm. 2016. Acesso em: 05 jan. 2017.

BELL, Daniel. O advento da sociedade pós-industrial. [s.l.]: Cultrix, 1977.

BOBBIO, Norberto. Estado, Governo, Sociedade: para uma teoria geral da política. 9. ed. São Paulo: Paz e Terra, 2001.

BOBBIO, Norberto. Direita e Esquerda. São Paulo: UNESP, 2001.

CASTELLS, Manuel. A Era da Informação: Economia, Sociedade e Cultura. A Sociedade em Rede. São Paulo: Paz e Terra, 1999. Vol. 1.

CASTELLS, Manuel. A galáxia da Internet: reflexões sobre a Internet, os negócios e a sociedade. Rio de Janeiro: J. Zahar, 2003.

COSTA, Judith Martins. Os direitos fundamentais e a opção culturalista do novo código Civil. In: SARLET, Ingo Wolfgang (org.). Constituição, Direitos Fundamentais e Direito Privado. Porto Alegre: Livraria do Advogado, 2006. 
CUNHA, Paulo Ferreira da. Direito Constitucional Geral: uma perspectiva lusobrasileira. São Paulo: Método, 2007.

CUNHA, Paulo Ferreira da. Repensar a Política: Ciência \& Ideologia. 2. ed. Coimbra: Almedina, 2007.

CUNHA, Paulo Ferreira da. Direito Internacional. Raízes \& Asas. Prefácio de Marcílio Toscano Franca Filho, Posfácio de Sérgio Ricardo Fernandes de Aquino. Belo Horizonte: Forum, 2017.

FERRAZ JÚNIOR, Tércio Sampaio. Introdução ao estudo do direito: técnica, decisão, dominação. São Paulo: Atlas, 1998.

FINLEY, Moses. "Introdução". FINLEY (org.). O legado da Grécia: uma nova avaliação. Brasília: Ed. UnB, 1998.

FIORILLO, Celso Antonio Pacheco. O Direito da Antena em Face do Direito Ambiental no Brasil. São Paulo: Fiúza, 2009.

FLUSSER, Vílem. Lingua e Realidade. 3. ed. São Paulo,. São Paulo: Annablume, 2007.

GIDDENS, Anthony. A transformação na intimidade. São Paulo: UNESP, 1993.

GOIS JUNIOR, José Caldas. O direito na era das redes: a liberdade e o delito no ciberespaço. Bauru: EDIPRO, 2001.

GROSSI, Paolo. Mitologias jurídicas da modernidade. 2. ed. Florianópolis: Fundação Boitex, 2007.

HAEBERLE, Peter. El Estado Constitucional. Estudo introdutório de Diego Valadés, trad. e índices de Héctor Fix-Fierro. México: Universidad Nacional Autónoma de México, 2003.

HABERMAS, Jürgen. Direito e democracia: entre facticidade e validade. 4.ed. Trad. de Flávio Beno Siebeneichler, Rio de Janeiro: Tempo Brasileiro, 1997. Vol. 1

HAESBAERT, Rogério. O Mito da Desterritorialização. 2. ed. Rio de Janeiro: Bertrand Brasil, 2006. 
HOUAISS, Antônio. Pequeno Dicionário Houaiss da Língua Portuguesa Rio de Janeiro: Moderna, 2016.

INELLAS, Gabriel Cesar Zacarias. Crimes na internet. São Paulo: Juarez de Oliveira Ltda, 2004.

JACOBS, Edgar P. A Armadilha Diabólica. Trad. Paula Caetano. Porto: Asa, 2008.

LEMOS, André. Cibercidade: As cidades na cibercultura. [S.1.]: E-papers, 2004.

KAMINSKI, Omar. (Org.). Internet Legal: o direito na tecnologia da informação Doutrina e Jurisprudência. Curitiba: Juruá, 2005.

KELSEN, Hans. Teoria Pura do Direito. 7. ed. Tradução de João Baptista Machado. São Paulo: Martins Fontes, 2006.

MACHADO, João Baptista. Introdução ao Direito e ao Discurso Legitimador. [s.l.]: Almedina, 2016.

MARÉS, Carlos Frederico. A função social da terra. Porto Alegre: Sérgio Antonio Fabris, 2003.

MORAES, Maria Celina B. A caminho de um Direito Civil Constitucional. Revista Estado, Direito e Sociedade, São Paulo, v. 1, jul./set. 1991. Disponível em: www. idcivil.com.br/pdf/biblioteca4.pdf. Acesso em: 10 dez. 2016.

MUÑOZ, Francisco Puy, Teoria Topica de Los Derechos Humanos. [s.l.]: Colex. Editorial Constitucion y Leyes, 2012.

OLIVEIRA, Irineu de Souza. Programa de Direito Romano. Canoas, RS: ULBRA, 1998.

PAESANI, Liliana Minardi. Direito e Internet: liberdade de informação, privacidade e responsabilidade civil. São Paulo: Atlas, 2012.

PERLINGIERI, Pietro. Perfis do Direito Civil: introdução ao Direito Civil Constitucional. 2. ed. Tradução de Maria Cristina De Cicco. Rio de Janeiro: Renovar, 2002. 
PREDIGER, Carin. A noção de sistema no direito privado e o código civil como eixo Central In: COSTA, Judith Martins (org.). A reconstrução do Direito Privado. São Paulo: Revista dos Tribunais, 2002.

PUY, Francisco. Tópica Jurídica: Tópica de Expressiones. México: Porrúa, 2006.

ROCHA, Cármem Lúcia Antunes. O princípio constitucional da Função Social da propriedade. In: BACELLAR FILHO, Romeu Felipe (coord.). Direito Administrativo Contemporâneo: Estudos em memória ao professor Manoel de Oliveira Franco Sobrinho. Belo Horizonte: Fórum, 2004.

ROVER, Aires J. Governo eletrônico: uma introdução. 2012. Disponível em: http://www.egov.ufsc.br/portal/conteudo/texto-governo-eletr\%C3\%B4nico-umaintrodu\%C3\%A7\%C3\%A3o. Acesso em: 27 set. 2016.

ROVER, Aires José. (org.). Direito e Informática. SP: Manole, 2004.

SALDANHA, Nelson. 0 jardim e a praça. 2. ed. rev. e atual. Rio de Janeiro: Atlântica, 2005.

SAUSSURE, Ferdinand. Curso de linguística geral. 26. ed. Tradução de Antônio Chelini, José Paulo Paes e Izidoro Blikstein. São Paulo: Cultrix, 1995.

SILVA, Virgílio Afonso da. A constitucionalização do direito: os direitos fundamentais nas relações entre particulares. São Paulo: Malheiros, 2005.

SILVEIRA, Michele Costa da. As grandes metáforas da bipolaridade. In: COSTA, Judith Martins (org.). A reconstrução do direito privado. São Paulo: Revista dos Tribunais, 2002.

SOARES, Rogério Ehrhardt. Direito Público e Sociedade Técnica. Coimbra: Ed. Biblioteca Jurídica, Atlântida, 1969.

Recebido em: 03/03/2018

Aceito em: 12/02/2019 